\title{
CRACKING ASSESSMENT IN CONCRETE STRUCTURES BY DISTRIBUTED OPTICAL FIBER
}

\begin{abstract}
In this paper, a method to obtain crack initiation, location and width in concrete structures subjected to bending and instrumented with an OBR system (Optical Backscattered Reflectometer) is proposed. Continuous strain data with high spatial resolution and accuracy are the main advantages of the OBR system. These characteristics make this Structural Health Monitoring (SHM) technique a useful tool in early damage detection in important structural problems. In the specific case of reinforced concrete structures, which exhibit cracks even in-service loading, the possibility to obtain strain data with high spatial resolution is a main issue. In this way, this information is of paramount importance concerning the durability and long performance and management of concrete structures.

The proposed method is based on the results of a test up to failure carried out on a reinforced concrete slab. Using test data and different crack modelling criteria in concrete structures, simple non-linear finite element models were elaborated to validate its use in the localization and appraisal of the crack width in the testing slab.
\end{abstract}

KEYWORDS : Distributed Optical Fiber Sensor, Non-linear FEM,Cracking detection.

\section{INTRODUCTION}

Structural Health Monitoring (SHM) can be described as a process of implementing a damage identification strategy ${ }^{1}$. In the specific case of concrete structures, damage is closely related to the presence of cracks. Because of inherent weakness in tension, cracks can be observed in reinforced concrete structures even in-service loading. On the other hand, cracks usually appear in concrete surfaces due to the corrosion of the passive and active reinforcement. Therefore, early detection of 
damage, its localization and characterization (crack width) are very important parameters in the safety, maintenance and durability of concrete structures.

The crack width measurement is a main issue in damage detection. Visible cracks not only affect the aesthetics, cracks of excessive widths can contribute to the corrosion of the reinforcement ${ }^{2}$. Early detection of these cracks before they become visible is of high interest for a correct preventive maintenance of concrete structures.

Until recently, conventional monitoring methods that were used to perform crack detection had serious limitations. The most common was to perform visual inspections and /or to use discrete sensors that generally were not able to locate existing cracks. In fact, the use of discrete sensors has very serious limitations since it is not known a priori where the crack could appear. The main problem is not being able to locate and especially to quantify cracking patterns in a timely manner.

During the past decades, the development of structural monitoring has produced a wide variety of measurement systems and new sensors. Monitoring systems with more compact sizes, easy installation and use, but especially with new measurement capabilities, have been implemented. Within this diversity, monitoring systems based on the use of fiber optic sensors have gained an important place and their use is increasingly being accepted. Their advantages and limitations regarding the use of traditional mechanical and electrical sensors have been widely discussed in a number of publications on this subject. ${ }^{3,4,5}$

One of the new possibilities has been to use the optical fiber itself not only as a conductive medium of information, but as a sensitive mean to gather information. Considering this idea, the optical fiber becomes a sensor with thousands of measurement points, giving the user the possibility of obtaining measurements distributed along a certain length. This has led to monitoring systems with distributed optical fiber, having the possibility to detect, localize and measure with high precision and in a timely manner, the damage on a monitored structure. ${ }^{6,7}$ 
In the specific case of concrete structures, much of the structural damage that is to be identified is manifested by the appearance of cracks. This is why to detect, to locate and mainly to obtain the crack width becomes of greater relevance. Crack width can be also related to damage due to corrosion in the reinforcing steel ${ }^{8}$. However, since the appearance of cracks is a phenomenon that cannot be predicted a priori, very often evaluating their effects is complicated and costly when using traditional techniques. The possibility to have monitoring systems that allow to accurately locate and to obtain crack width dimensions has become a challenge.

This paper presents a method to obtain the average crack width in concrete structures subjected to bending. The proposed method is based on information acquired from a monitoring system with distributed optical fiber and is an extension of the method as presented in Rodriguez et $\mathrm{al}^{9}$. In fact, in the presented paper, the technique to assess the crack width is introduced. Additionally, an extensive comparison between the results of the proposed method and those obtained with other experimental techniques and FEM models is provided, including the compression zone. In this way, the checking of the results becomes more reliable.

\section{AVAILABLE METHODS FOR CRACK WIDTH MEASUREMENT}

\section{Visual Inspection}

Visual inspection is generally performed by using simple measuring devices, which have predetermined ranges of crack width measurements. Occasionally, these devices have lens that serve to amplify and improve the viewer's vision. ${ }^{10}$

\section{Image Processing}

Currently, techniques to acquire crack patterns through images are widely used, such as highresolution photographic cameras and software development, allowing imaging processing. These techniques have allowed the incorporation of monitoring systems whose application to experimental 
testing in the laboratory, as well as in the field, is beginning. ${ }^{11}$ Irrespective of the characteristics of these monitoring systems, in most cases, it is necessary to implement sophisticated methodologies to ensure the usefulness of the acquired images. ${ }^{12}$

In the case of obtaining crack widths in concrete structures, a very important aspect is the setting of the camera monitoring system, since when using the images to determine crack widths within millimeter levels; it must be ensured that the reference is always the same. This aspect may limit the use of these systems only for the measurement of cracks in small areas, or its use in laboratory tests, where work conditions and lighting can be controlled in a more optimal manner. In field applications, the versatility of these systems is limited because they must adapt to a number of conditions which are often very different, as well as aspects of lighting and weather conditions.

\section{Smart film Technique}

Another possibility that currently exists for measuring crack widths in concrete structures is through the technique known as Smart film. ${ }^{13}$ This technique is based on the simulation of the sensitivity of the skin of an animal, when creating a surface made from enameled copper wires, which intersect each other to simulate a sensory system. The smart film adheres to the surface of concrete with epoxy resin. Once the smart film is adhered to the concrete surface under study, through an electrical signal processor and a sophisticated algorithm for interpretation, the produced signals within the smart film that run through the enameled copper wire, are monitored. When a crack in the concrete appears, it is detected by the system and can be localized. This technique has been tested both the laboratory and an in-service bridge. ${ }^{13}$ The results obtained so far, have been the product of a series of major adjustments in the surface that simulates the sensory system. However, these results seem to be still limited to the detection and localization of cracks in sections with low length, without even quantifying crack widths. 


\section{Distributed optical Fiber}

Several experiences have demonstrated the feasibility of using the Distributed Optical Fiber Sensor system (DOFSs) and OBR (Optical Backscattered Reflectometer) technique in the structural health monitoring of existing concrete structures. ${ }^{14,}$ 15, 16 This Structural Health Monitoring (SHM) technique has shown to be very effective in the detection and localization of initiating cracking in the concrete, either because of the increasing applied external loads or because of environmental actions as corrosion. Also, the distributed strain data has been used to calculate the deflection in selected points of a bridge. ${ }^{15}$ However, the continuous (in space) monitoring of the strain along the optical fiber, including the crossing of a crack provides additional information that can be used in further SHM applications. Billon et al. ${ }^{17}$ presented a methodology to perform a quantitative strain measurement with DOFSs when strain in the optical fiber may differ from actual strain in the structure, due to shear transfer through the intermediate material layers between the optical fiber and the host material. Hoult and Regier ${ }^{18}$ investigated the feasibility of distributed fiber optic strain sensors installed either internally or externally to detect pitting corrosion in reinforced concrete beams. Their tests show how localised deterioration can be detected and quantified with embedded sensing fibres. Rodriguez et al. ${ }^{9}$ showed how the experimental strains data obtained with and OBR measuring system can be used to locate cracking before being visually observable. In the present paper, it is described how these data can be used to obtain crack width. This information is of paramount importance concerning durability and long term performance of concrete structures.

\section{OPTICAL BACKSCATTERED REFLECTOMETER}

A DOFSs is usually applied by measuring physical changes along the length of a sensing fiber. This is a distinctive property of DOFSs with respect to other measuring techniques, because it can replace a several number of discrete sensors. DOFSs are generally based on the measuring of some perturbations induced on the light that travels inside the fiber. In this intrinsic mechanism, three 
main physical principles take place in an optical fiber: Raman, Brillouin and Rayleigh scattering. Raman and Brillouin processes present dependence to external physical fields. Raman scattering has an intrinsic dependence on the temperature of the fiber, which has been used in DOFSs to perform continuous measurement of temperature with high accuracy. Brillouin scattering is simultaneously sensitive to strain and temperature, therefore, these two parameters could be obtained through this scattering process ${ }^{19}$.

However, there are two techniques based on Brillouin scattering: Brillouin Optical Time Domain Reflectometry (BOTDR) based on a Spontaneous Brillouin scattering and Brillouin Optical Time Domain Analysis (BOTDA) based on Stimulated Brillouin scattering ${ }^{20}$. The main difference between them is that BOTDA is achieved by using two optical waves (pump and probe signal). The interaction between them, leads to a larger scattering efficiency, resulting in an energy transfer and an amplification of the probe signal ${ }^{7}$. Therefore, these systems are used to monitor in very long distances, up to some kilometers. ${ }^{21}$ However, they have limitations in detecting very small cracks and in accurately providing the size of the crack. ${ }^{22,23}$

Conversely, Rayleigh scattering in optical fiber is independent of almost any external physical field for a wide range of condition. DOFSs based on Rayleigh technique, scattering is used only to detect propagation effects as attenuation or gain, phase interference and polarization variation, which are the real sensing mechanisms ${ }^{19}$. In the specific case of DOFSs for strain and temperature monitoring, phase interference is the physical phenomenon used to the implementation of the monitoring system based on Rayleigh scattering process ${ }^{24}$.

Recently, the Rayleigh scattering has been applied to the measurement of strain and temperature with a spatial resolution around millimeters ${ }^{25}$. The main issue is the use of the so-called Optical Backscattered Reflectometry (OBR). OBR is based on a frequency-domain technique, optical 
frequency-domain reflectometry (OFDR) that uses a tunable laser and an interferometer to probe reflections. Frequency domain techniques are usually used to analyse systems on the component-or module-level when very high resolution (microns) analysis of the reflections in a system is required. Optical backscatter differs from other frequency-domain techniques in that is sensitive enough to measure levels of Rayleigh backscatter in standard single mode fiber. The OBR uses swept wavelength interferometry (SWI) to measure the Rayleigh backscatter as a function of length in an optical fiber with high spatial resolution (at a strain and temperature resolution as fine as 1 microstrain and $0.1{ }^{\circ} \mathrm{C}$ ). An external stimulus (like a strain or temperature change) causes temporal and spectral shifts in the local Rayleigh backscatter pattern. These temporal and spectral shifts can be measured and scaled to give a distributed temperature or strain measurement ${ }^{16}$.

\section{OBR setup}

Basically, the OBR monitoring systems include an active part and a passive part. The active part is a monitoring unit that throws a beam of light, usually a laser of adjustable frequency, to which an optical fiber cable is connected, which is the passive part of the system. The characteristics of the beam of light traveling within the fiber are known, and they change depending on the temperature and the strain at which the fiber is subjected. These changes are detected at the back-scattered light, which are then stored in the monitoring unit, analysed and eventually become deformation data and temperature variation of the surface under study ${ }^{25}$. This process is shown in Fig. 1. 


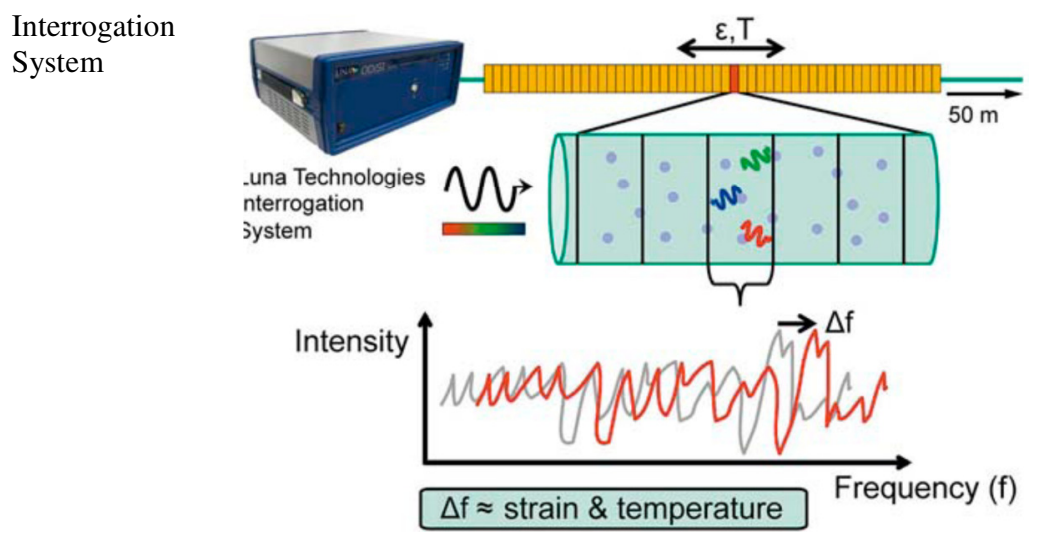

Fig. 1. Rayleigh scattering measurement process. ${ }^{25}$

The specifications of the monitoring system as used in the tests presented in the next section are as follows: Spatial resolution: Sub-millimeter spatial resolution (default gauge length $1 \mathrm{~cm}$ ), Accuracy in strain measurement: $+/-2$ microstrain, $+/-2^{\circ} \mathrm{C}$, Interval between measurement points: $1 \mathrm{~cm}$, Length range of sensor: $50 \mathrm{~m}$

As shown in the following section, the availability of a continuous measurement of the strain along a concrete surface, including the presence of cracking, can be used to warn about the initiation of cracking, its location and the assessment of crack width.

\section{EXPERIMENTAL VALIDATION}

The OBR measuring system was deployed in a concrete slab of an experimental campaign conducted at the Structural Technology Laboratory of the Technical University of Catalonia (UPCBARCELONATECH) ${ }^{26,27}$. Dimensions of the reinforced concrete slab were $5.6 \mathrm{~m}$ span length, $1.60 \mathrm{~m}$ width and $0.285 \mathrm{~m}$ thickness. The slab was simply supported at both ends and the loading was applied using an actuator of $1 \mathrm{MN}$ capacity in the mid-span of the slab. The slab was monitored with OBR sensors at the top and bottom surfaces, exactly in the four stretches as shown in Fig. 2. The optical fiber used was a single-mode fiber (SMF) type with a $50 \mathrm{~m}$ length. A coating of a polymer (polyimide) was used to protect the fiber against scratches and environmental attack. Firstly, bond areas were cleaned and free from grease. A commercial glue was applied to the bond 
area (on the concrete surfaces), avoiding to apply adhesive excess. The glue used was a one part component (without mixing) chemical type ethyl cyanoacrylate, with low viscosity. The adhesive was applied to one of the bond surfaces, avoiding the use of tissue or a brush to spread the adhesive. The slab was also monitored in the reinforcing steel bars with dynamic strain gauges. Deflection was measured at the centre and ends of the slab using linear displacement transducers (LVDT). Joint opening at the middle of the slab was measured from their initiation using magnetic transducer “Temposonics” as seen in Fig. 2 (right).
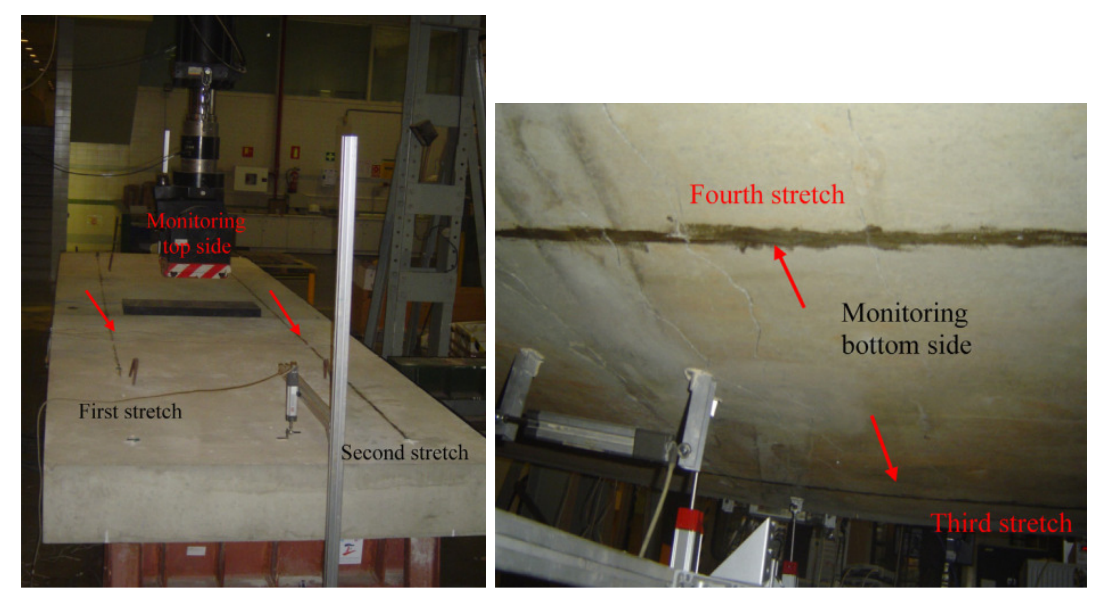

Fig. 2. Load arrangement and location of OBR sensors (left: top view, right: bottom view).

\section{Strain Distribution}

During the test, the strain distribution along the slab was measured by the OBR system. The measured results in the third and fourth stretch at the bottom of the slab at different load levels (from $50 \mathrm{kN}$ to $110 \mathrm{kN}$ with increments of $20 \mathrm{kN}$ ) are shown in Figs. 3 and 4. The measurements are in good agreement with the results predicted by the analysis, and apparent strain distribution peaks appear first at $50 \mathrm{kN}$ (corresponding to the theoretical cracking load), around the middle of the span. The location of the peaks corresponds quite well to the crack location visually observed. Based on these data and other experimental results coming from the standard monitoring by straingages and LVDT, firstly a method to obtain the mean crack width of reinforced slab is developed. Then, three non-linear finite element models of the slab were proposed and calibrated with the 
objective to obtain the most accurate model to predict cracking patterns where no instrumentation was deployed in the test.
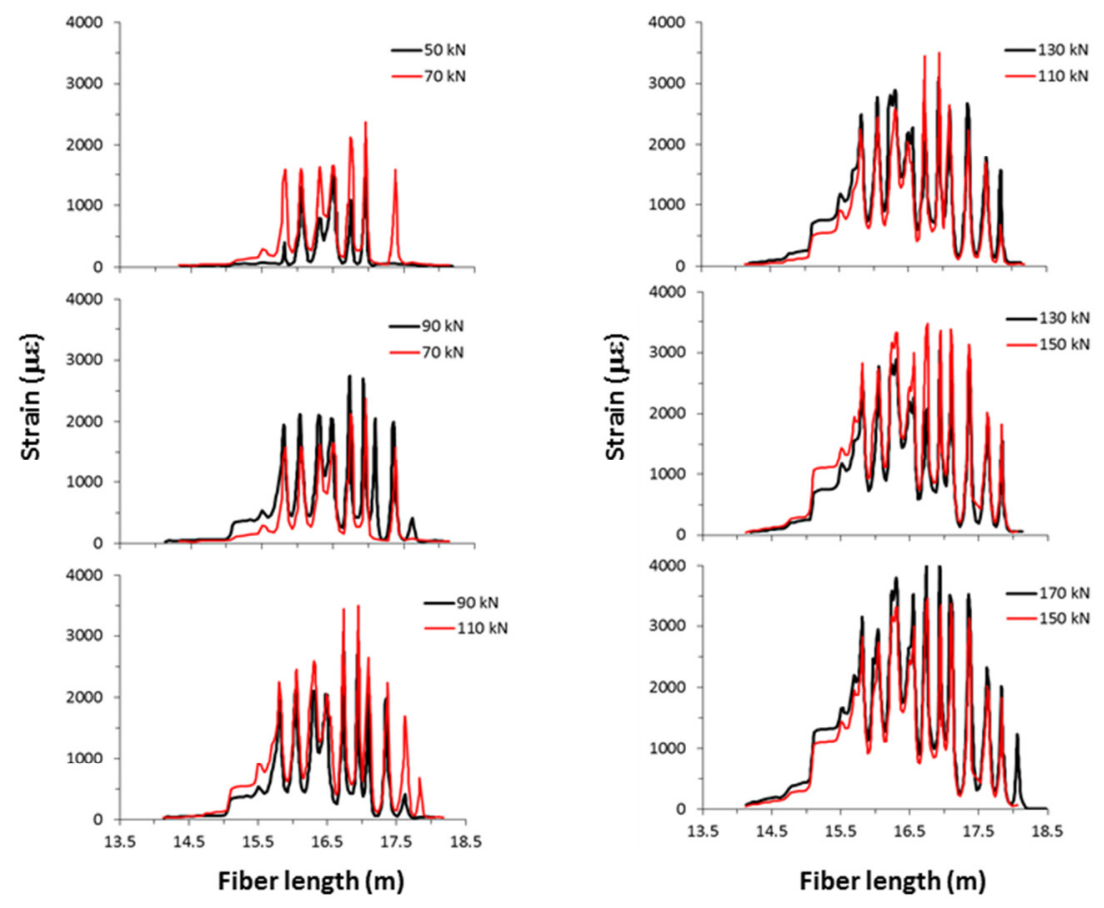

Fig. 3. Strain along the fiber length (third stretch bottom side) from $50 \mathrm{kN}$ to $170 \mathrm{kN}$. 

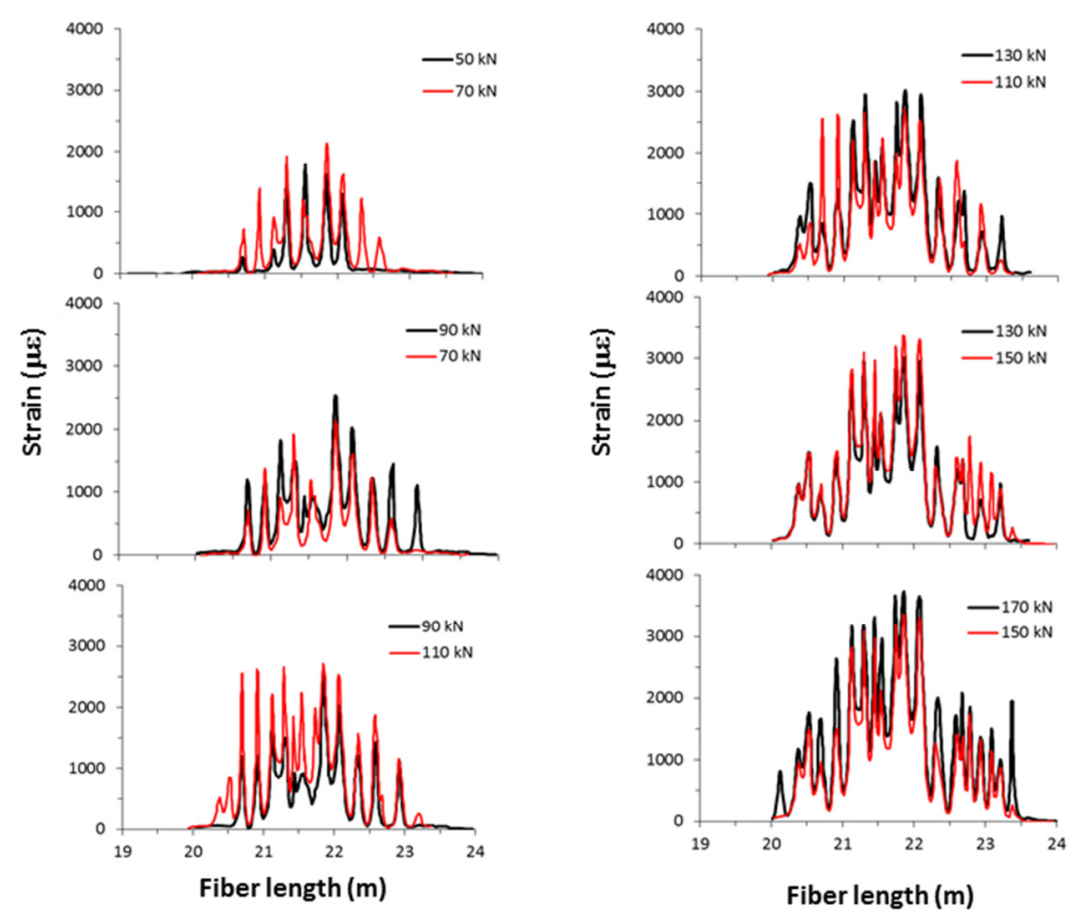

Fig. 4. Strain along the fiber length (fourth stretch bottom side) from $50 \mathrm{kN}$ to $170 \mathrm{kN}$.

\section{CRACK WIDTH ASSESSEMT}

By obtaining the strain in the concrete surface along the fiber, a formulation can be drawn to obtain the average crack width. The formulation is based on integrating the distribution of the experimental strains registered along a characteristic length L. As described in Fig. 5, in order to integrate and obtain an average strain $\left(\varepsilon_{\text {mean }}\right)$, the strain distribution $\left(\varepsilon_{\mathrm{OBR}}\right)$ is defined from a strain value corresponding to the tensile strength of the concrete $\left(\varepsilon_{\mathrm{fct}}\right)$. This is the strain value where the crack appears. Under this criterion, firstly an average deformation from the area under the curve of the total strain over the cracked length $\mathrm{L}$ is defined according to equation 1(see Fig. 5). L corresponds to the length of the element where $\varepsilon_{\mathrm{OBR}}>\varepsilon_{\mathrm{fct}}$. 


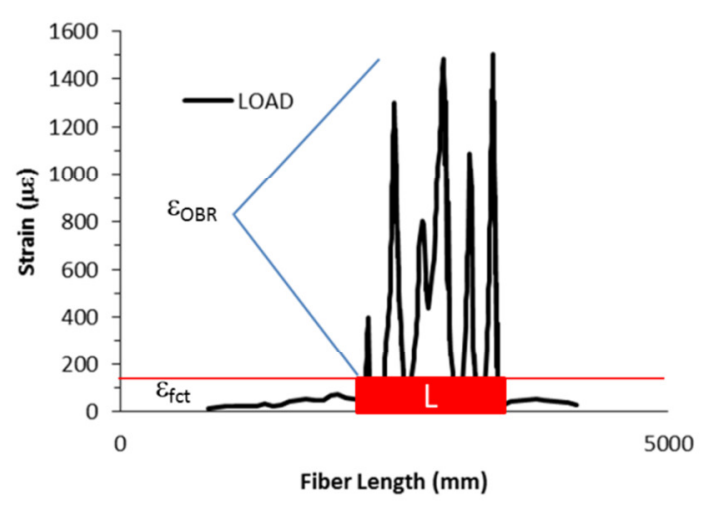

Fig. 5. Definition of parameters to calculate the crack width

$$
\varepsilon_{\text {mean }}=\frac{1}{L} \int_{0}^{L} \varepsilon_{O B R} d L
$$

This average strain has two components: the deformation to the concrete cracking and starting here, the deformation due to the cracks in the cracked area. Therefore, from equation (2) we can calculate $\Sigma \mathrm{w}$, where w comprises the sum of the widths of all cracks in the cracked area.

$$
\varepsilon_{\text {mean }}=\varepsilon_{f c t}+\frac{\sum w}{L}
$$

In this way, we can define an average crack width in the following way:

$$
w_{\text {mean }}=\frac{\sum w}{N}
$$

Being $\mathrm{N}$ the number of cracks. $\mathrm{N}$ can be also obtained from the test results, counting the peaks in the strain profile ( see Fig. 5).

The method can be applied to different load levels in order to know the variation of crack width as a function of the load increase. A comparison between the average crack width obtained experimentally in the middle of the span by the crack width transducers and those obtained with the equations 1 to 3 for different load levels registered with the OBR system is shown in Table 1 . The 
values of columns 2 and 3 in the Table 1 are the values of the transducers 1 and 2, respectively. These transducers are located in two different points of the cross-section, close to the edge of the slab one, and in the central part the other (see Figs. 2 and 6). For this reason, in column 4 the mean of these values is calculated, as representative of the crack width in the section under investigation.

It should be noticed that this comparison is done only at mid-span because this was the only section instrumented with sensors to measure crack opening as show in Fig. 6. The results show a quite acceptable correspondence between the experimental results and the proposed method.

Table 1. Crack width at mid-span.

\begin{tabular}{cccccc}
$\begin{array}{c}\text { Load } \\
(\mathbf{k N})\end{array}$ & $\begin{array}{c}\text { Crack Width } \\
\text { Transducer1 } \\
(\mathbf{m m})\end{array}$ & $\begin{array}{c}\text { Crack Width } \\
\text { Transducer2 } \\
(\mathbf{m m})\end{array}$ & $\begin{array}{c}\text { Arithmetic } \\
\text { Mean } \\
(\mathbf{m m})\end{array}$ & $\begin{array}{c}\text { OBR } \\
\text { Stretch3 } \\
(\mathbf{m m})\end{array}$ & $\begin{array}{c}\text { OBR } \\
\text { Stretch4 } \\
(\mathbf{m m})\end{array}$ \\
\hline \hline 50 & 0.058 & 0.099 & 0.079 & 0.062 & 0.065 \\
\hline 70 & 0.077 & 0.154 & 0.116 & 0.112 & 0.101 \\
\hline 90 & 0.105 & 0.125 & 0.115 & 0.149 & 0.127 \\
\hline 110 & 0.166 & 0.147 & 0.157 & 0.190 & 0.163 \\
\hline 130 & 0.296 & 0.200 & 0.248 & 0.237 & 0.209 \\
\hline 150 & 0.370 & 0.267 & 0.319 & 0.298 & 0.246 \\
\hline 170 & 0.439 & 0.337 & 0.388 & 0.354 & 0.213 \\
\hline
\end{tabular}
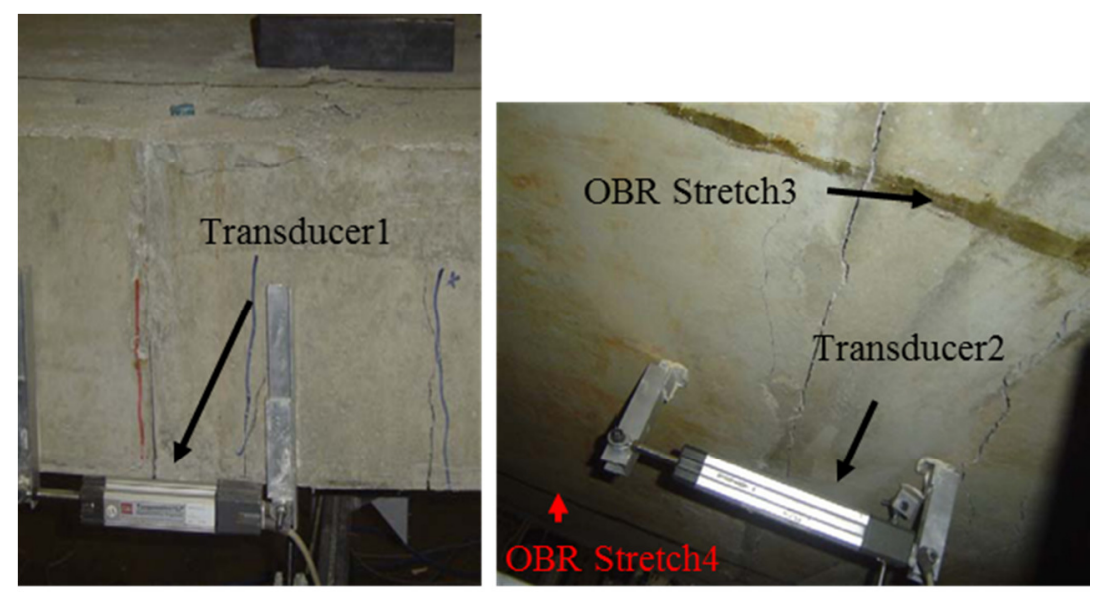

Fig. 6. Location of transducers 1 and 2 (left: front of the slab, right: bottom and middle of the slab). 


\section{NON-LINEAR FINITE ELEMENT MODEL}

As mentioned, crack width at mid-span of the slab was measured using two magnetic transducers (Fig. 6). Therefore, a direct comparison between crack width obtained with transducers and OBR respectively, can only be checked at these points. For this reason, a Finite Element Model (FEM) able to represent the behaviour of cracked concrete was built and calibrated using the available experimental data coming from the displacement transducers and strain gauges. With the results from the FEM, more conclusions can be drawn on the performance of the optical fiber sensor in other cross-sections different from the mid-span.

The cracked behavior of reinforced concrete structures may be modelled by discrete or smeared crack models. In the first case, the element remains always continuous and without damage. The cracks are modelled by displacement discontinuities between elements. In this way, the cracks can only be developed through the element boundaries, and to obtain the direction of crack propagation, the FEM mesh has to be progressively adapted or interface elements have to be used. The analyses with these models becomes very cumbersome and therefore are used to follow the propagation of singular cracks, but are not normally used to model a global crack pattern.

The smeared crack models are defined by: a failure criteria (constant or linear), a transfer across the crack (total, constant or variable) and a law to smooth the material behavior ( brittle, linear, exponential). The cracked material is worked out as continuous and the discontinuity of the displacement field due to cracking is extended over the whole element. Therefore, these models are a non-discrete global approximation to a process that is essentially discrete. However, they derive acceptable results in practical applications ${ }^{28,29}$. This approach is useful because does not impose any cracking direction. These models can be fixed or with rotation. In the first case, the cracking 
direction is the same during the all computational process (bending cracks). In the second case, they allow the co-rotation of the principal strain axes (shear-bending cracks) ${ }^{29}$.

The concrete slab is modelled with 2D plain stress elements, with a total of 821 nodes and 239 square elements with 9 Gauss points. The reinforcing bars are modelled by elements with perimeter and sectional area identical to the real re-bars. The upper and bottom reinforcements consists of 7 bars each, with 16 and $20 \mathrm{~mm}$ diameter respectively. The concrete cover is $30 \mathrm{~mm}$. (see Fig. 7) The steel yield strength is $550 \mathrm{MPa}$. The concrete properties are those obtained in the tests ${ }^{26}$. The compressive strength is $\mathrm{f}_{\mathrm{c}}=51.31 \mathrm{MPa}$, and the tensile strength $\mathrm{f}_{\mathrm{t}}=4.00 \mathrm{MPa}$. The elasticity modulus is $33,147 \mathrm{MPa}$.

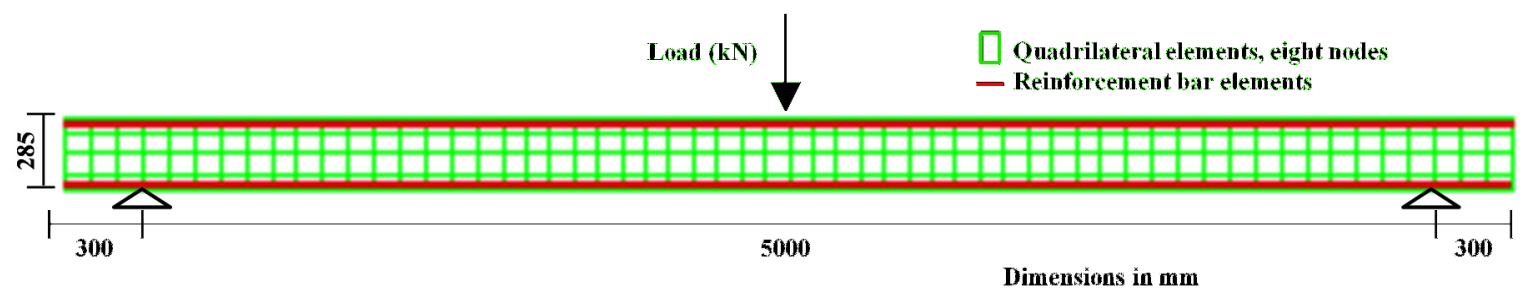

Fig. 7. Mesh of Finite Element Model.

When the sensing cable is protected with a significant coating and attached to the surface with adhesive layers, strain profiles measured in the optical fiber may differ from actual strain in the structure. In these cases, fiber optic sensor needs to be evaluated to provide accurate measurements. Several mechanical testing, pull out tests and FEM numerical modelling had been developed to validate different methodologies to evaluate these effects ${ }^{17,30}$.

In the present case, the FEM model does not include the fiber stretches because the optic sensor used in the test, was a fiber of $0.2 \mathrm{~mm}$ of diameter with a simply polyimide-coated, without any special protective coating in the sensing cable. The fiber optic used in the test is shown in Fig. 8. Due to the reduced dimensions of the fiber and de adhesive layer, they were not included in the modelling. 


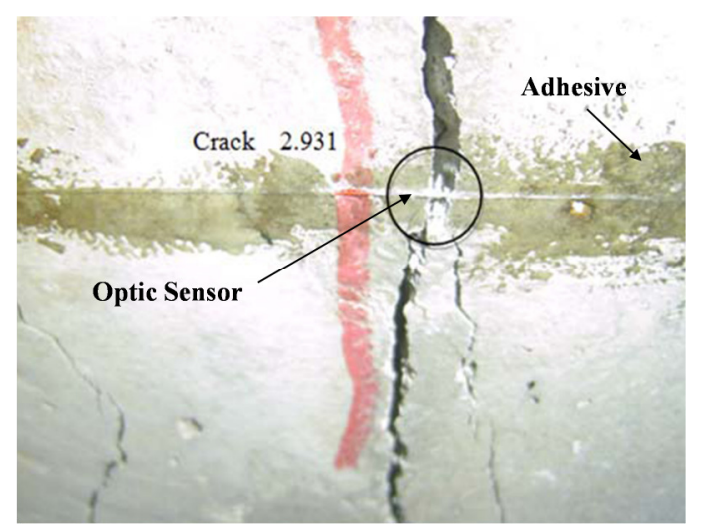

Fig. 8. View of fiber optic sensor and layer of adhesive

The DIANA software ${ }^{31}$ is used to model the test with 3 different scenarios : brittle behavior of concrete (Fig. 9 left) with rotating cracks (FEM1) or fixed cracks (FEM2), and tensile strength with exponential decrease (Fig. 9 center) (FEM3). In all cases the stress-strain law in compression is according to Spanish Code ${ }^{32}$ adjusted by a multi-linear law (Fig. 9 right).

\section{Results: model calibration}

In table 2, the measured deflections are presented in the mid-span section and those coming from the three FEM models. The models FEM1 and FEM2 give very accurate results. The results are graphically displayed in Fig. 10. Fig. 11 shows the results obtained in each load step by the 3 models. It is clearly visible the change of stiffness at the level of $50 \mathrm{kN}$ for FEM1 and FEM2, which corresponds to the appearance of the first cracks. In FEM3 cracking appears at around $100 \mathrm{kN}$, despite the deflection at failure becomes more similar to the other 2 models. Based on the results of deflection, model FEM3 is disregarded from future comparisons. 

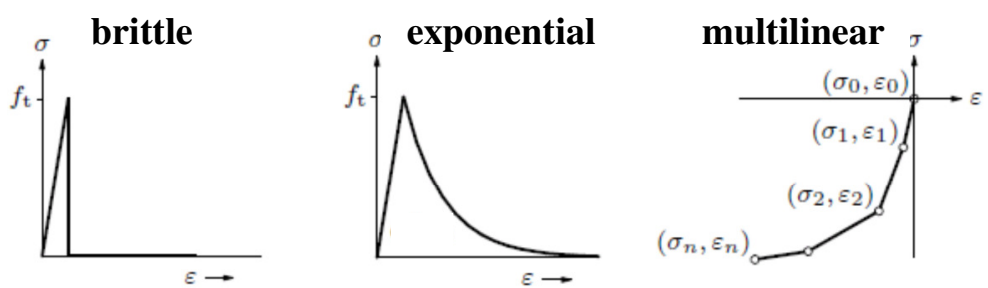

Fig. 9. Tension and compression behaviour of concrete for FEM models

Table 2. Deflections at mid-span

\begin{tabular}{ccccc}
$\begin{array}{c}\text { Load } \\
(\mathbf{k N})\end{array}$ & $\begin{array}{c}\text { Experimental } \\
\text { Deflection } \\
(\mathbf{m m})\end{array}$ & $\begin{array}{c}\text { FEM 1 } \\
\text { Deflection } \\
(\mathbf{m m})\end{array}$ & $\begin{array}{c}\text { FEM 2 } \\
\text { Deflection } \\
(\mathbf{m m})\end{array}$ & $\begin{array}{c}\text { FEM 3 } \\
\text { Deflection } \\
(\mathbf{m m})\end{array}$ \\
\hline \hline 20 & 0.498 & 0.584 & 0.584 & 0.584 \\
\hline 60 & 3.833 & 3.53 & 3.53 & 1.752 \\
\hline 100 & 10.166 & 11.38 & 10.5 & 5.548 \\
\hline 140 & 16.543 & 18.10 & 16.7 & 14.01 \\
\hline 180 & 22.324 & 25.11 & 22.6 & 21.31 \\
\hline $204-220$ & 29.227 & 29.3 & 29.3 & 29.3 \\
\hline
\end{tabular}

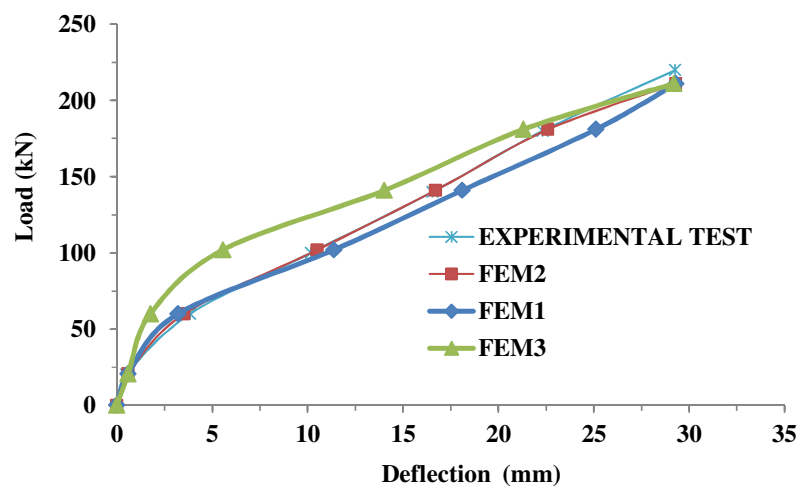

Fig. 10. Experimental and FEM deflections

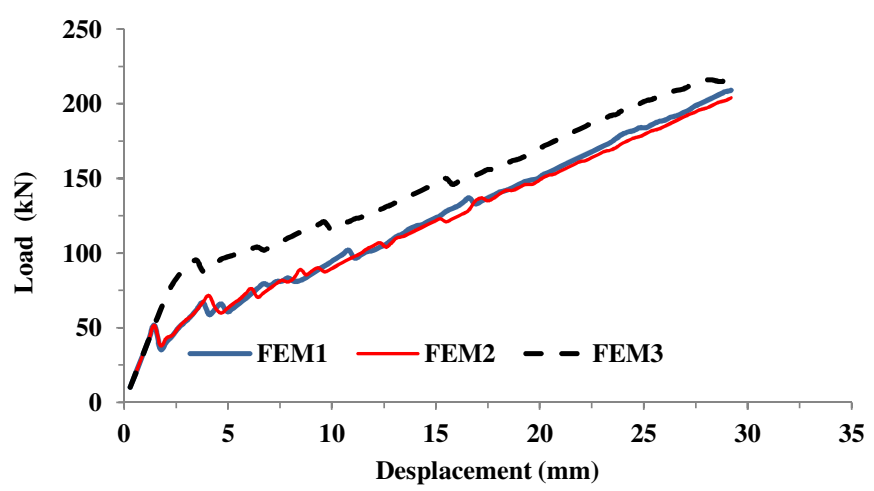

Fig. 11. FEM max deflections in the middle of the slab 


\section{Crack pattern, location and width}

Fig. 12 shows the strain obtained in the first stretch (upper part of the slab, compression zone) of the sensor and their comparison with the results obtained with FEM2 for 2 load levels. For the load level of $50 \mathrm{kN}$, the maximum experimental value $(222 \mu \varepsilon)$ is slightly higher than the theoretical one ( $190 \mu \varepsilon$ ). For the load level of $110 \mathrm{kN}$, the corresponding values are 410 and $455 \mu \varepsilon$. From figure 12, we may conclude that the comparison is acceptable in the whole fiber length. The maximum measured compressive strain in the concrete for a load level of $243 \mathrm{kN}$ was $2400 \mu \varepsilon$. This value is close to the maximum compressive strain in concrete (between 2000 and $3500 \mu \varepsilon$ ), what reflects the fact that the failure mode of the slab was due to failure in compression of the concrete at a load level of $255 \mathrm{kN}$.
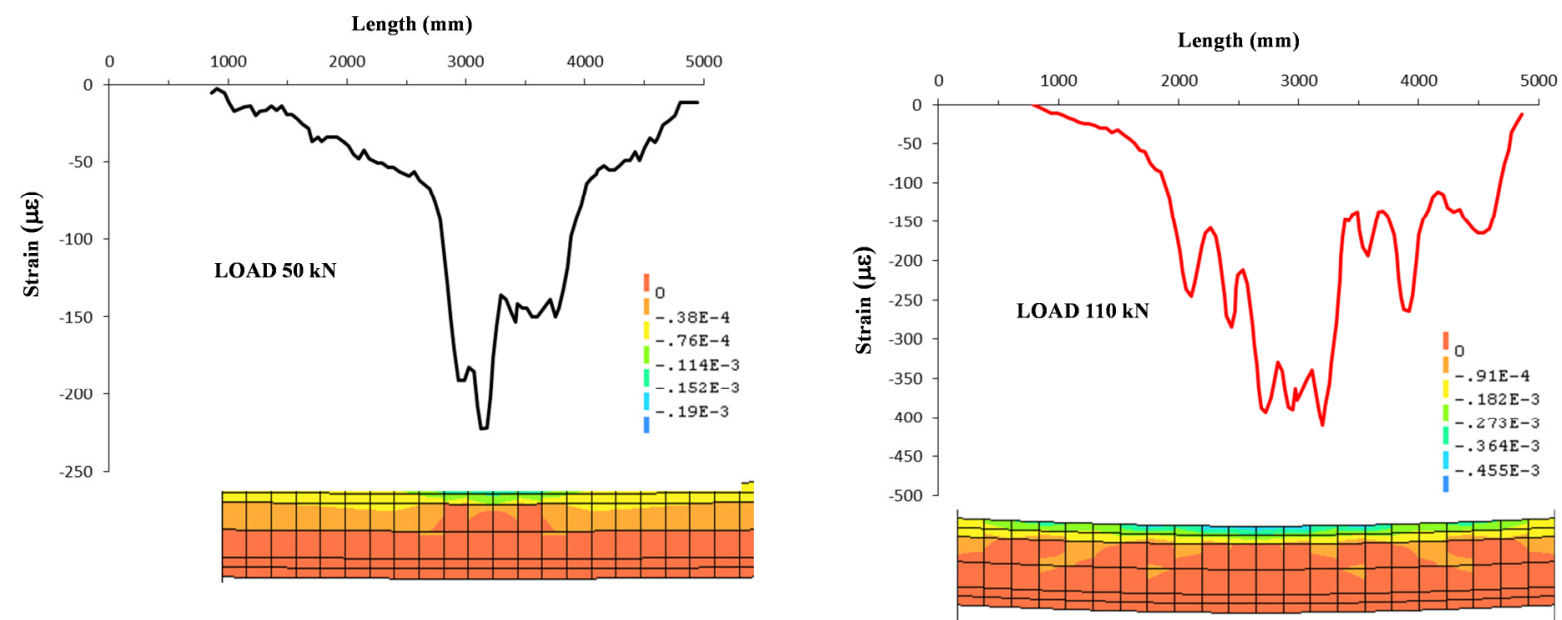

Fig. 12. Comparison of experimental and theoretical compression strain along span

Tables 3 and 4 show the strains measured by the OBR system and those predicted by the FEM models at those points where cracking appeared (peaks) for load levels of 50 and $110 \mathrm{kN}$. The first column in the tables indicates the location of each observed crack in the test. A value equal to zero in table 3 means that the corresponding crack had not yet appeared for this level of load. 
From tables 3 and 4, one may conclude that the best approximation to the real strains is obtained with model FEM2 (crack pattern without rotation), as expected for a test zone mainly in bending. In Fig. 13 we can see the comparison between the experimental crack pattern and the one obtained with FEM2 for a load level of $110 \mathrm{kN}$ at mid-span. In Fig. 14, the experimental and theoretical (FEM2) strain laws are compared for two levels of load, showing a good fit. This confirms again the correct performance of the OBR system in measuring strain even in cracked zones. The theoretical values are obtained linking the points of cracking strain at the Gauss points of interpolation and taking into account the dimension of the corresponding finite element. The location of these points in the model is the closest to the peaks of strain identified in the test. The OBR system detected an early cracking at low level of load around $50 \mathrm{kN}$. The crack width could be experimentally obtained by the standard instrumentation but only in the points where the sensors were deployed (mid-span). These values are shown in table 5 for different load levels and compared with the values obtained with the OBR system and the theoretical models FEM1 and FEM2. Again FEM2 provides the most accurate results.

Table 3. Micro strains at $50 \mathrm{kN}$

\begin{tabular}{cccc}
$\begin{array}{c}\text { Peaks:distance } \\
\text { from the left end } \\
(\mathbf{m m})\end{array}$ & $\begin{array}{c}\boldsymbol{\mu \varepsilon} \\
\text { OBR }\end{array}$ & $\begin{array}{c}\boldsymbol{\mu \varepsilon} \\
\text { FEM1 }\end{array}$ & $\begin{array}{c}\boldsymbol{\mu} \boldsymbol{\varepsilon} \\
\text { FEM2 }\end{array}$ \\
\hline \hline 1953 & 0 & 0 & 0 \\
\hline 2258 & 400 & 594 & 997 \\
\hline 2456 & 1300 & 741 & 1134 \\
\hline 2758 & 800 & 570 & 997 \\
\hline 2932 & 1480 & 567 & 0 \\
\hline 2991 & 0 & 0 & 997 \\
\hline 3185 & 1090 & 699 & 1223 \\
\hline 3382 & 1500 & 587 & 0 \\
\hline 3525 & 0 & 0 & 0 \\
\hline 3795 & 0 & 0 & 0 \\
\hline 4066 & 0 & 0 &
\end{tabular}


Table 4. Micro strains at $110 \mathrm{kN}$

\begin{tabular}{cccc}
$\begin{array}{c}\text { Peaks: distance } \\
\text { from the left end } \\
(\mathbf{m m})\end{array}$ & $\begin{array}{c}\mu \varepsilon \\
\text { OBR }\end{array}$ & $\begin{array}{c}\mu \varepsilon \\
\text { FEM1 }\end{array}$ & $\begin{array}{c}\boldsymbol{\mu} \varepsilon \\
\text { FEM2 }\end{array}$ \\
\hline 1953 & 800 & 2950 & 1814 \\
\hline 2258 & 2250 & 3002 & 1910 \\
\hline 2456 & 2450 & 2963 & 1385 \\
\hline 2758 & 2590 & 2279 & 2086 \\
\hline 2932 & 2040 & 2324 & 2091 \\
\hline 2991 & 1550 & 1201 & 2962 \\
\hline 3185 & 3450 & 2326 & 2126 \\
\hline 3382 & 3500 & 802 & 2369 \\
\hline 3525 & 2650 & 966 & 2962 \\
\hline 3795 & 2240 & 2129 & 2022 \\
\hline 4066 & 1700 & 1295 & 2031 \\
\hline 4270 & 675 & 700 & 1090 \\
\hline
\end{tabular}

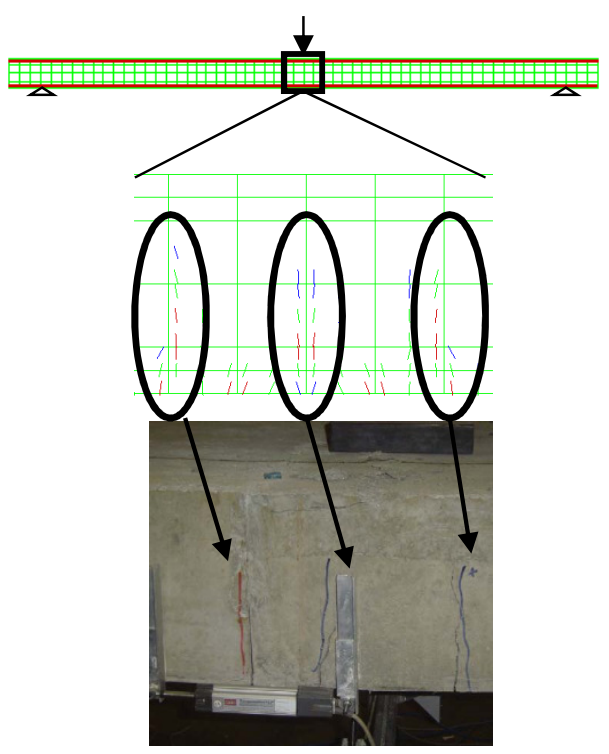

Fig. 13. Comparison of experimental and theoretical crack patterns at mid-span 

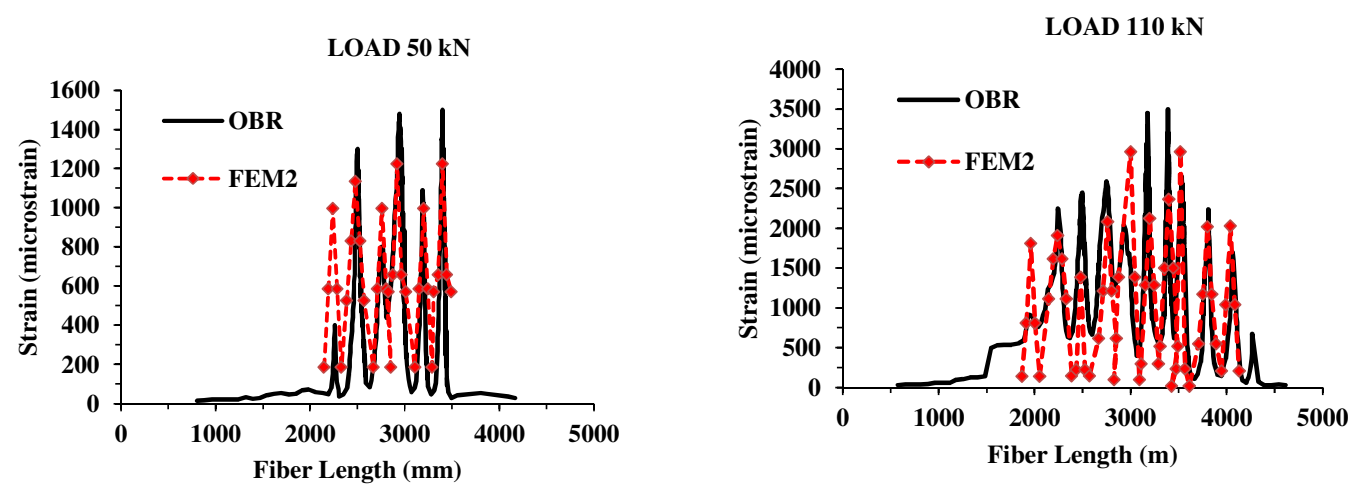

Fig. 14. Comparison of experimental and theoretical strain along span

Table 5. Crack width at mid-span

\begin{tabular}{ccccc}
$\begin{array}{c}\text { Load } \\
\text { Load(kN) }\end{array}$ & $\begin{array}{c}\text { Crack Width } \\
\text { Transducers } \\
(\mathbf{m m})\end{array}$ & $\begin{array}{c}\text { Crack Witdth } \\
\text { OBR } \\
(\mathbf{m m})\end{array}$ & $\begin{array}{c}\text { Crack Width FEM1 } \\
(\mathbf{m m})\end{array}$ & $\begin{array}{c}\text { Crack Width } \\
\text { FEM2 } \\
(\mathbf{m m})\end{array}$ \\
\hline \hline 50 & 0.079 & 0.062 & 0.049 & 0.052 \\
\hline 60 & 0.094 & --- & 0.070 & 0.106 \\
\hline 70 & 0.116 & 0.112 & 0.132 & 0.138 \\
\hline 90 & 0.115 & 0.149 & 0.126 & 0.118 \\
\hline 100 & 0.130 & --- & 0.174 & 0.152 \\
\hline 111 & 0.157 & 0.190 & 0.202 & 0.206 \\
\hline 130 & 0.248 & 0.237 & 0.230 & 0.240 \\
\hline 140 & 0.284 & --- & 0.245 & 0.259 \\
\hline 150 & 0.319 & 0.298 & 0.304 & 0.296 \\
\hline 170 & 0.388 & 0.354 & 0.422 & 0.371 \\
\hline 180 & 0.420 & --- & 0.482 & 0.409 \\
\hline 220 & 0.594 & --- & 0.552 & 0.533 \\
\hline
\end{tabular}

\section{CONCLUSIONS}

With the use of the monitoring systems with distributed optical fiber, the limitations of discrete sensors to locate cracks and measure their width are covered, since such sensors have to rely on the extrapolation of results and in some cases on the use of very sophisticated structural analysis techniques to diagnose the local and global state of a whole structure. 
The experimental data obtained in the test allowed to calibrate a non-linear model for the concrete slab. Once calibrated, the model can be used to predict cracking location and width in different parts of the specimen. This is demonstrated by comparison with the experimental results.

The OBR system deployed allowed to predict the formation of the initial cracking, the location of the cracks and also their width based on the continuous monitoring of strain along the optical fiber. The obtained results compare very well with the available experimental values obtained from the rest of the sensors as well as with the visual inspection and the values predicted by the non-linear finite element models. This validates the use of OBR system as a method for SHM of concrete structures.

\section{REFERENCES}

1. Liu Y and Nayak S. Structural Health Monitoring: State of the Art and Perspectives. JOM, Vol. 64 No.7, 2012.Published on line July 10, 2012.

2. Coronelli D, Hanjari K.Z and Lundgren K. Severely Corroded RC with Cover Cracking. Journal of Structural Engineering. ASCE pp 221-232, February 2013.

3. Casas JR and Cruz JS. Fiber Optic Sensors for Bridge Monitoring. ASCE Journal of Bridge Engineering, 8 (6), pp 362-373, November/December 2003.

4. Culshaw B. Fiber Optic Sensors in Smart Structures: Achievements, Challenges and Prospects. SPIE Vol. 7982. Smart Sensor Phenomena, Technology, Networks and Systems. 798202-1 798202-9, 2011.

5. Glisic B and Inaudi D. Fibre optic methods for structural health monitoring. Chichester, UK: John Wyley \& Sons 2007.

6. Ravet F, Briffod F, Glisic B, Nikles M and Inaudi D. Submillimeter Crack Detection With Brillouin-Based Fiber-Optic Sensors. IEEE Sensors Journal. Vol. 9, No. 11, November 2009.

7. Glisic B, Inaudi D. Development of method for in-service crack detection based on distributed fiber optic sensors. Structural Health Monitoring 11 (2) pp 161-171, 2011. 
8. Vidal T, Castel A, François R. Analyzing crack width to predict corrosion in reinforced concrete. Cement and Concrete Research. 34 pp 165-174, 2004.

9. Rodriguez G, Casas JR and Villalba S. Assessing cracking characteristics of concrete structures by Distributed Optical Fiber and Non-Linear Finite Element Modelling. EWSHM- $7^{\text {th }}$ European Workshop on Structural Health Monitoring, Nantes France, July 2014.

10. D.J Haavik. Evaluating concrete cracking by measuring crack width. Publication \#C900553. The Aberdeen Group. 1990.

11. Nazmul I and Matsumoto T. High Resolution COD image analysis for health monitoring of reinforced concrete structures through inverse analysis. International Journal Solids Structures. 45 pp159-174, 2008.

12. Jahanshani MR, Masri SF and Sukhatme S. Multi-image stitching and scene reconstruction for evaluating defect evolution in structures. Structural Health Monitoring International journal, 10 pp 643-57, 2011.

13. Zhang B, Wang S, Li X, Zhang X, Yang G and Qiu M. Crack width monitoring of concrete structures based on smart film. Smart Materials and Structures 23, 2014.

14. Villalba S and Casas JR. Monitorización y salud estructural. Aplicación de la fibra óptica distribuida (OBR) en estructuras de hormigón. V Congreso de Puentes y Estructuras de ACHE. Barcelona, España, Octubre 2011.

15. Villalba V, Casas JR and Villalba S. Application of OBR fiber optic technology in structural health monitoring of Can Fatjó Viaduct (Cerdanyola de Vallés-Spain).VI International Conference on Bridge Maintenance, Safety and Management, IABMAS 12, Stresa, Italy, July 2012.

16. Villalba S and Casas JR. Application of optical fiber distributed sensing to health monitoring of concrete structures. Mechanical Systems and Signal Processing. 39 :441-451, 2013. 
17. Billon A, Henault JM, Quiertant M, Taillade F, Khadour A, Martin RP, Benzarti K. Quantitative Strain Measurements with Distributed Fiber Optic Systems: Qualification of a Sensing Cable Bonded to the Surface of a Concrete Structure. EWSHM- $7^{\text {th }}$ European Workshop on Structural Health Monitoring, Nantes France, July 2014.

18. Hoult A. and Regier R. Concrete deterioration detection using distributed sensors. Proceedings of the ICE-Structures and Buildings, September 2014.

19. Palmieri L and Schenato L. Distributed Optical Fiber Sensing Based on Rayleigh Scattering. The Open Optics Journal, 7, (Suppl-1, M7)104-127, 2013.

20. Zeni L. Optical fiber distributed sensors: a tool for in-situ structural and environmental monitoring. www.corista.eu/docs/optical_fiber.pdf

21. Enckell M, Glisic B, Myrvoll F and Bergstrand B. Evaluation of large-scale bridge strain, temperature and crack monitoring with distributed fibre optic sensors. Journal of Civil and Structural Health Monitoring, 1, pp 37-46, 2011.

22. Bastianini F, Matta F, Galati N and Nanni A. A Brillouin smart FRP material and strain data post processing software for structural health monitoring through laboratory testing and field application on a highway bridge. Smarts Structures and Materials: Nondestructive Evaluation for Health Monitoring and Diagnostics. Proc. SPIE Vol. 5765, pp 600-611. 2005.

23. Minardo A, Persichetti G, Testa G and Zeni L.Long term structural health monitoring by Brillouin fibre-optic sensing: a real case. Journal of Geophysics and Engineering-, 9, S64-S68. 2012.

24. Froggatt M and Moore J. High-Spatial-Resolution Distributed Strain Measurement in Optical Fiber with Rayleigh Scatter. Appl Opt; 37(10): 1735-40, 1998

25. Samiec D. Distributed fibre-optic temperature and strain measurement with extremely high spatial resolution. Photonik international, 2012. 
26. Villalba S. Diseño y validación experimental de uniones mediante superposición de lazos de armaduras en viaductos de hormigón de sección transversal evolutiva. Optimización del proceso constructivo. Ph. D. Thesis. Civil Engineering Department, Technical University of Catalonia, UPC. Barcelona, Spain, July 2010.

27. Villalba S, Casas J.R, Aparicio AC and Villalba V. New structural joint by rebar looping applied to segmental bridge construction. Fatigue strength tests. Journal of Bridge Engineering (ASCE), Vol. 18, N. 11, pp. 1174-1188, 2013.

28. Rots JG, Nauta P, Kusters GMA and Blaauwendraad J. Smeared crack approach and fracture localization in concrete. HERON, Delft, v.30, n.1, 1985.

29. Rots JG and Blaauwendraad J. Crack models for concrete: discrete or smeared? Fixed, multidirectional or rotating? HERON, Delft, v.34, n.1, 1989.

30. Li D, Ren L, Li H. Mechanical property and strain transferring mechanism in optical fiber sensors. www.interchopen.com

31. DIANA. Finite Element Analysis. User's Manual release 9.4.4. Analysis Procedures, 2011.

32. EHE. Normativa: Instrucción del Hormigón Estructural, Ministerio de Fomento, Madrid, 2008. 